\title{
Idebenone-Induced Recovery of Glycerol-3-Phosphate and Succinate Oxidation Inhibited by Digitonin
}

\author{
H. RAUCHOVÁ ${ }^{1,2}$, M. VOKURKOVÁ ${ }^{1,2}$, Z. DRAHOTA ${ }^{1,3}$ \\ ${ }^{1}$ Institute of Physiology, Academy of Sciences of the Czech Republic, Prague, ${ }^{2}$ Center for \\ Cardiovascular Research, Prague, ${ }^{3}$ Center for Applied Genomics, Prague, Czech Republic
}

Received January 5, 2012

Accepted January 20, 2012

On-line April 5, 2012

\begin{abstract}
Summary
Digitonin solubilizes mitochondrial membrane, breaks the integrity of the respiratory chain and releases two mobile redoxactive components: coenzyme Q (CoQ) and cytochrome $c$ (cyt $c$ ). In the present study we report the inhibition of glycerol-3phosphate- and succinate-dependent oxygen consumption rates by digitonin treatment. Our results show that the inhibition of oxygen consumption rates is recovered by the addition of exogenous synthetic analog of CoQ idebenone (hydroxydecylubiquinone; IDB) and cyt c. Glycerol-3-phosphate oxidation rate is recovered to $148 \%$ of control values, whereas succinatedependent oxidation rate only to $68 \%$. We find a similar effect on the activities of glycerol-3-phosphate and succinate cytochrome $c$ oxidoreductase. Our results also indicate that succinate-dependent oxidation is less sensitive to digitonin treatment and less activated by IDB in comparison with glycerol3-phosphate-dependent oxidation. These findings might indicate the different mechanism of the electron transfer from two flavoprotein-dependent dehydrogenases (glycerol-3-phosphate dehydrogenase and succinate dehydrogenase) localized on the outer and inner face of the inner mitochondrial membrane, respectively.
\end{abstract}

\section{Key words}

Hyperthyroid liver mitochondria • Oxygen consumption rate • Coenzyme Q $\bullet$ Cytochrome $c$

\section{Corresponding author}

H. Rauchová, Institute of Physiology, Academy of Sciences of the Czech Republic, Vídeňská 1083, 14220 Prague 4, Czech Republic. Fax: ++420 241062 488. E-mail: rauchova@biomed.cas.cz

\section{Introduction}

Digitonin is a well known and frequently used glycoside that solubilizes mitochondrial membranes by specific binding to cholesterol areas (Geelen 2005). It breaks the integrity of the respiratory chain and consequently releases respiratory complexes. Generally, it is supposed that the inhibition of respiratory chain activity by detergents is accompanied by the release of two mobile redox-active molecules, i.e. cytochrome $c$ (cyt $c$ ) and coenzyme Q (CoQ). A recent investigation on respirasome from mouse liver mitochondria showed that mitochondrial respiratory chain supercomplexes still maintained some residual succinate oxidase activity. The transfer of electrons from Complex II to Complex IV correlated with the finding that the membrane-bound mobile carriers (cyt $c$ and $\mathrm{CoQ}$ ) could be detected in isolated supercomplexes (Acín-Pérez et al. 2008).

We aimed to find to what extent the oxidation of succinate and glycerol-3-phosphate is inhibited by digitonin treatment because flavoprotein-dependent glycerol-3-phosphate dehydrogenase (GPDH, EC 1.1.99.5) is localized on the outer face of the inner mitochondrial membrane and flavoprotein-dependent succinate dehydrogenase (SDH, EC 1.3.99.1) on the inner face. Both enzymes feed electrons to the respiratory chain CoQ pool. However, the previous papers suggested the absence of Q-binding protein of GPDH (Cottingham and Ragan 1980, Rauchová et al. 1992), which was postulated by $\mathrm{Yu}$ and $\mathrm{Yu}$ (1982) and $\mathrm{Yu}$ et al. (1978) for SDH. The content of GPDH (in comparison with other mitochondrial dehydrogenases) largely varies in different mammalian tissues with the highest activity in brown 
adipose tissue of newborn, hibernating or cold-adapted animals. In liver tissue GPDH is very low; however, its content is markedly increased by thyroid hormones action as was firstly shown by Lee and Lardy (1965) and Lee et al. (1959).

Because of the extreme hydrophobicity of natural CoQ (Lenaz and Genova 2009) its less hydrophobic synthetic analog idebenone (hydroxydecylubiquinone, IDB) with a 10-carbon side chain ending by a hydroxyl group was developed (Zs-Nagy 1990). It is used for the therapy of several mitochondrial diseases, e.g. Friedreich's ataxia (Di Prospero et al. 2007, Lynch et al. 2010), Leigh syndrome (Haginoya et al. 2009) or Leber's hereditary optic neuropathy (Mashima et al. 2000). IDB facilitates the flux of electrons along the respiratory chain and increase the production of adenosine triphosphate (Sugiyama and Fujita 1985). Moreover, it has potent antioxidant action and can serve as a protective scavenger for reactive oxygen species (Rauchová et al. 2006). Our previous data showed that IDB strongly activates glycerol-3-phosphate oxidation inhibited by endogenous or added free fatty acids (Rauchová et al. 2008). Therefore we choose IDB as a possible substance for the recovery of glycerol-3phosphate and succinate oxidase activities inhibited by digitonin. The aim of present study was to assess the concentration dependence of digitonin inhibitory effect and to estimate to which extent IDB and cyt $c$ supplements are able to restore the enzyme activities inhibited by digitonin.

\section{Material and Methods}

\section{Materials}

Digitonin was obtained from Merck. A stock solution of digitonin $(50 \mathrm{mg} / \mathrm{ml})$ was prepared in dimethylsulfoxide (DMSO). Idebenone was kindly provided by Takeda (Osaka, Japan). Stock solution of IDB was prepared in absolute ethanol. Tris(hydroxymethyl)aminomethane, EDTA, glycerol-3phosphate, succinate, ADP, cytochrome $c$ (horse), 3,3',5triodo-L-thyronine (sodium salt, $\mathrm{T}_{3}$ ) and bovine serum albumin (BSA) were purchased from Sigma-Aldrich Co (USA). All other reagents were of the purest grade commercially available.

\section{Animals}

Experiments were performed on adult male Wistar rats weighting 300-350 g from the authorized rat- breeding unit at our institute housed at $23 \pm 1{ }^{\circ} \mathrm{C}$ and 12 -h light-dark cycle periods (6:00 AM to 6:00 PM) with ad libitum access to water and a complete laboratory diet. The maintenance and handling of experimental animals were in accordance with the EU Council Directive 86/609EEC and the investigation was approved by the Expert Committee of the Institute of Physiology, Academy of Sciences of the Czech Republic, Prague, Czech Republic.

\section{Alteration of thyroid status}

Hyperthyroid status was induced in rats and maintained 3-4 weeks. Rats received intraperitoneal injection of 3,3',5-triodo-L-thyronine 3 times a week (0.15 $\mathrm{mg} / \mathrm{kg}$ body weight). Hyperthyroid status was confirmed by the increased total serum $T_{3}$ levels, increased relative heart weight (heart weight/body weight), decreased relative thyroid gland weight (thyroid gland weight/body weight) and increased activity of GPDH as we showed previously (Rauchová et al. 2004, Rauchová et al. 2011a). The control (euthyroid) rats were age-matched littermates of the hyperthyroid rats.

\section{Mitochondria isolation}

Immediately after sacrifice, excised liver were properly cleaned, freed of connective tissue and placed in ice-cold isolation medium (250 mM sucrose, $10 \mathrm{mM}$ Tris- $\mathrm{HCl}$ and $1 \mathrm{mM}$ EDTA, $\mathrm{pH}$ 7.4). Liver was gently homogenized in a glass Teflon homogenizer with above medium and isolated by differential centrifugation according to Johnson and Lardy (1967). All procedures were carried out at $4{ }^{\circ} \mathrm{C}$. Experiments were performed on both fresh (intact) and frozen-thawed mitochondria stored at $-80^{\circ} \mathrm{C}$. Mitochondrial protein concentration was determined according to Folin method using BSA as a standard (Lowry et al. 1951).

\section{Mitochondrial oxygen consumption}

Oxygen consumption by mitochondria was measured at $30^{\circ} \mathrm{C}$ with a High Resolution Oxygraph (Oroboros, Austria) as we described previously (Rauchová et al. 2011a). Briefly, $2 \mathrm{ml}$ of incubation medium contained $100 \mathrm{mM} \mathrm{KCl,} 10 \mathrm{mM}$ Tris- $\mathrm{HCl}, 5 \mathrm{mM}$ K-phosphate, $3 \mathrm{mM} \mathrm{MgCl}$, $1 \mathrm{mM}$ EDTA (pH 7.4) and 0.12-0.16 mg protein $/ \mathrm{ml}$. Glycerol-3-phosphate or succinate were $10 \mathrm{mM}$, ADP $1.5 \mathrm{mM}$. Oxygen uptake was expressed as pmol oxygen/s/mg mitochondrial protein. 
Table 1. Glycerol-3-phosphate and succinate oxygen consumption rates in fresh and frozen-thawed mitochondria isolated from euthyroid and hyperthyroid rat liver.

\section{Mitochondria}

\section{Oxygen consumption rate}

\section{Glycerol-3-phosphate}

\section{Succinate}

\section{Fresh mitochondria \\ Euthyroid liver \\ Hyperthyroid liver}

$71 \pm 7$

$196 \pm 11 *$

$430 \pm 42$

Euthyroid liver

Hyperthyroid liver

\section{Frozen-thawed mitochondria}

In incubation medium glycerol-3-phosphate or succinate was $10 \mathrm{mM}$ and ADP $1.5 \mathrm{mM}$ (in the fresh mitochondria assay), glycerol-3phosphate or succinate was $10 \mathrm{mM}$ (in frozen-thawed mitochondria assay). Oxygen uptake is expressed as pmol oxygen/s/mg protein. Data are means \pm S.E.M. from at least five measurements, $* \mathrm{p} \leq 0.05$ compared with euthyroid liver.

\section{Determination of enzyme activities}

Glycerol-3-phosphate and succinate cyt $c$ oxidoreductase were determined spectrophotometrically at room temperature following the cyt $c$ reduction at $550 \mathrm{~nm}$ in $1 \mathrm{ml}$ of medium containing $50 \mathrm{mM} \mathrm{KCl}$, $20 \mathrm{mM}$ Tris- $\mathrm{HCl}, 2 \mathrm{mM} \mathrm{KCN}, 1 \mathrm{mM}$ EDTA and $0.05 \mathrm{mM}$ cyt $c$ (pH 7.4) using mitochondrial protein $0.9-1.3 \mathrm{mg} / \mathrm{ml}$. The reaction was started by addition of $25 \mathrm{mM}$ glycerol-3-phosphate or succinate. The results were expressed as nmol cyt $c / \mathrm{min} / \mathrm{mg}$ protein using the extinction coefficient of $19 \mathrm{mmol}^{-1} \mathrm{~cm}^{-1}$ for cyt $c$.

\section{Statistical analysis}

The data were expressed as means \pm SEM and significance of the differences was evaluated by ANOVA. Only values of $p \leq 0.05$ were considered statistically significant.

\section{Results}

Glycerol-3-phosphate and succinate oxygen consumption rates in euthyroid and hyperthyroid rat liver mitochondria

We compared oxygen consumption rates from fresh (intact) and frozen-thawed liver mitochondria isolated from euthyroid (control) and hyperthyroid rats (Table 1). In both fresh and frozen-thawed mitochondria from hyperthyroid rats glycerol-3-phosphate oxidation was about three fold higher than in control animals. Similarly, succinate oxidation was also significantly increased in triiodothyronine-treated rats, however, to a lower extent, by $67 \%$ and $38 \%$ in fresh and frozenthawed mitochondria, respectively.
The effect of cytochrome $c$ supplement on glycerol-3phosphate and succinate oxidation rate in frozen-thawed mitochondria

We evaluated the role of cyt $c$ in activation of glycerol-3-phosphate and succinate oxidation in frozenthawed mitochondria, where cyt $c$ was released from the membrane. Using frozen-thawed mitochondria isolated from hyperthyroid rats we could increase glycerol-3phosphate oxidation nearly 2 times and succinate oxidation more than 3 times by $20 \mu \mathrm{M}$ cyt $c$ supplements (Fig. 1A, B). In agreement with our previous findings on brown adipose tissue mitochondria, the significant additional increase of glycerol-3-phosphate oxidation was also reached by BSA (Rauchová et al. 2003). The rate of succinate oxidation by BSA was not changed.

The digitonin inhibition of glycerol-3-phosphate and succinate oxidation

We measured the inhibitory effect of digitonin on the glycerol-3-phosphate and succinate oxygen consumption rates in the presence of $40 \mu \mathrm{M}$ cyt $c$ (Fig. 2A, B). In the presence of $5 \mathrm{mg}$ digitonin $/ \mathrm{mg}$ mitochondrial protein both enzyme activities were inhibited to 15 and 25 $\%$ of original values of glycerol-3-phosphate and succinate oxygen consumption rate, respectively. However, oxygen consumption rate of succinate indicated more resistance at low digitonin concentrations (1-2 $\mathrm{mg}$ digitonin/mg mitochondrial protein).

The idebenone-induced recovery of digitonin-inhibited glycerol-3-phospate and succinate oxygen consumption rates

In further experiments we tested to what extent of 

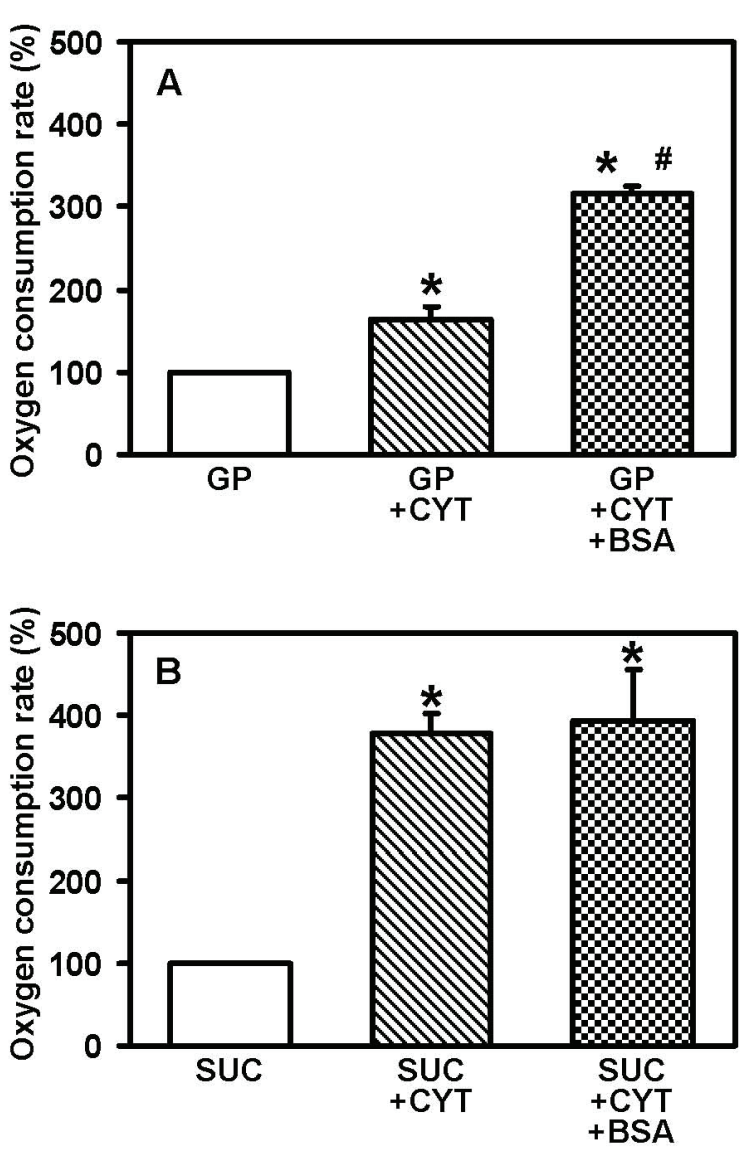

Fig. 1. (A) The effect of cytochrome $c$ and serum albumin in glycerol-3-phosphate oxygen consumption rate in frozen-thawed hyperthyroid rat liver mitochondria, (B) The role of cytochrome $c$ and serum albumin in succinate oxygen consumption rate in frozen-thawed hyperthyroid rat liver mitochondria. In incubation medium glycerol-3-phosphate (GP) or succinate (SUC) was $10 \mathrm{mM}$, cytochrome $c$ (CYT) $20 \mu \mathrm{M}$ and bovine serum albumin (BSA) $0.5 \mathrm{mg} / \mathrm{ml}$. Oxygen uptake is expressed as \% of control values. Data are expressed as means \pm SEM from at least five measurements and the significance of the differences was evaluated by ANOVA, $* \mathrm{p} \leq 0.05$ compared with GP/SUC, ${ }^{*} \mathrm{p} \leq 0.05$ compared with GP/SUC + CYT.

glycerol-3-phosphate and succinate oxygen consumption rates inhibited by digitonin could be recovered by supplement of IDB (Fig. 3A). Glycerol-3-phosphate oxygen consumption rate was increased after IDB supplement to $148 \%$ of control values. Inhibition of succinate oxygen consumption rate was also increased by IDB; however, the restoration was not complete and reached only $68 \%$ of control values (Fig. 3B). Similarly, the oxygen consumption rate of glycerol-3-phosphate could be restored by an addition of $\mathrm{CoQ}_{1}$ (Rauchová et al. 2011b).

The idebenone-induced recovery of digitonin-inhibited glycerol-3-phospate and succinate cytochrome $c$ oxidoreductases

In the last part of our experiments we evaluated
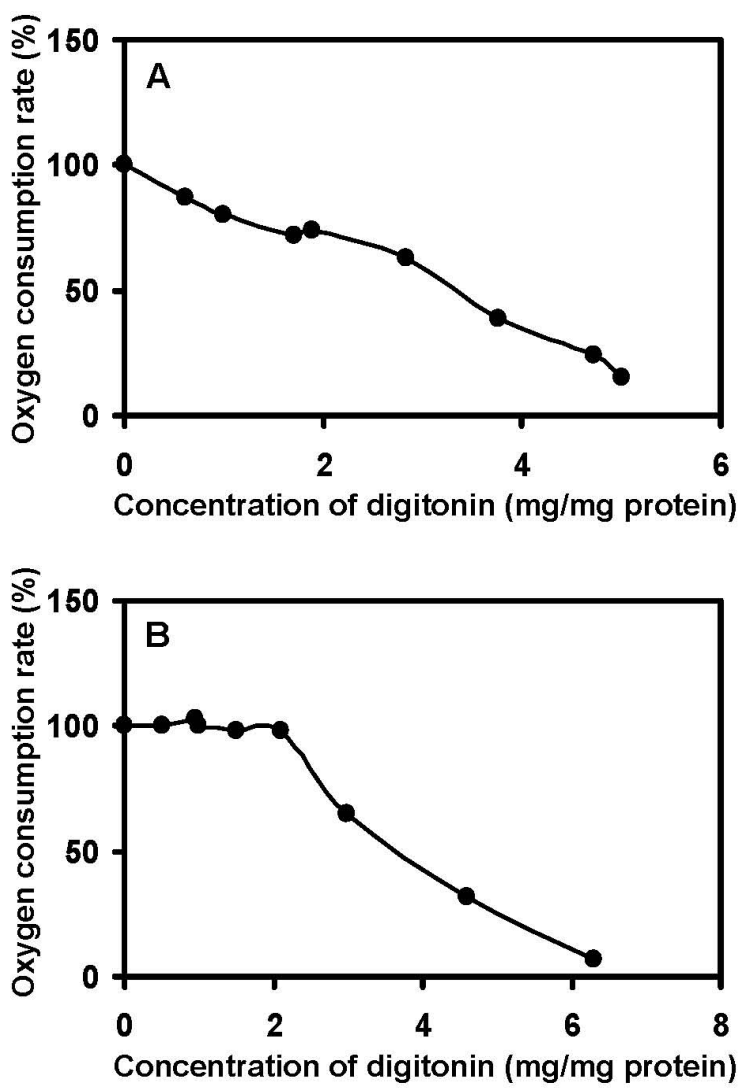

Fig. 2. (A) Digitonin inhibition of glycerol-3-phosphate oxygen consumption rate, (B) Digitonin inhibition of succinate oxygen consumption rate. In incubation medium glycerol-3-phosphate or succinate was $10 \mathrm{mM}$, cytochrome $c 20 \mu \mathrm{M}$.

the activating effect of IDB on glycerol-3-phosphate and succinate cyt $c$ oxidoreductase activities inhibited by digitonin (Fig. 4A, B). In agreement with previous data on oxygen consumption rate, glycerol-3-phosphate cyt $c$ oxidoreductase was more sensitive to digitonin action in comparison with succinate cyt $c$ oxidoreductase. Similarly, IDB recovery was better in the case of glycerol-3phosphate cyt $c$ oxidoreductase (Fig. 4A) in comparison with succinate cyt $c$ oxidoreductase (Fig. 4B).

\section{Discussion}

In the present study we showed the inhibition of glycerol-3-phosphate- and succinate-dependent oxygen consumption rates by digitonin and the recovery by cyt $c$ and IDB supplements.

Recently, the existence of supramolecular associations of the respiratory complexes was confirmed (Eubel et al. 2004, Lenaz and Genova 2010, Lenaz et al. 2010, Schägger and Pfeiffer 2000, Vonck and Schäfer 2009). However, the integrity of the respiratory chain is also dependent on two mobile carriers, i.e. CoQ that 

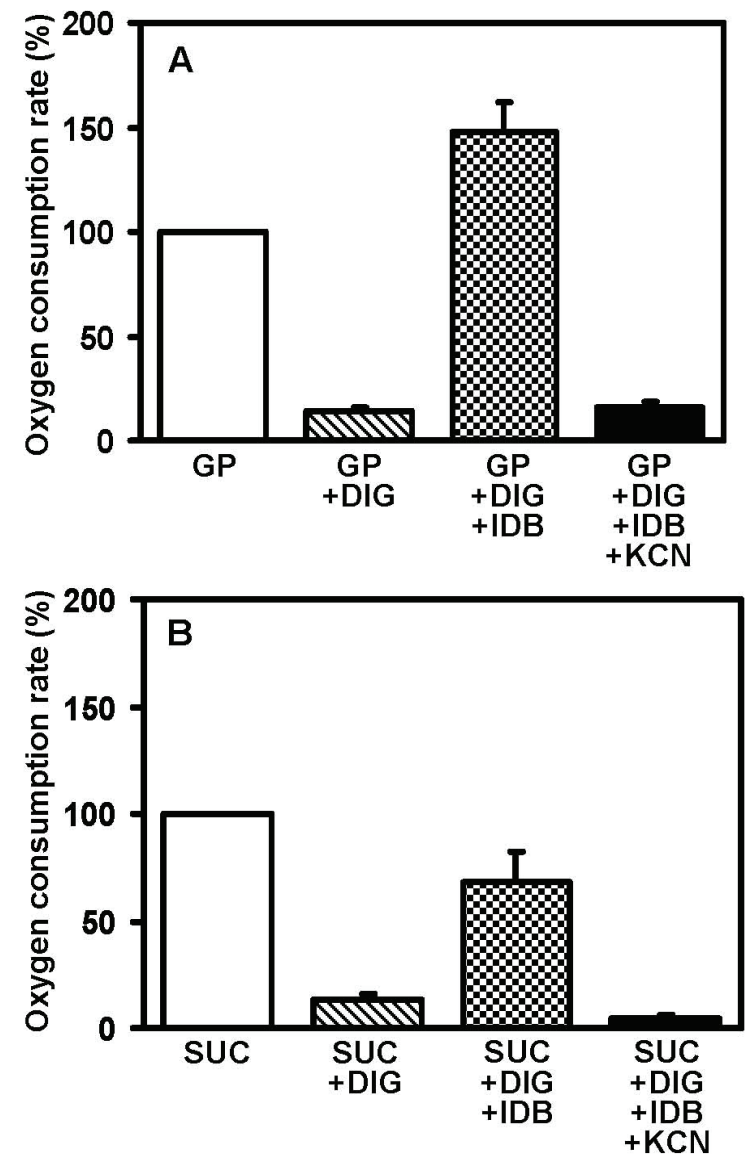

Fig. 3. (A) Digitonin inhibition and idebenone release of glycerol3-phosphate oxygen consumption rate, (B) Digitonin inhibition and idebenone release of succinate oxygen consumption rate. In incubation medium glycerol-3-phosphate (GP) or succinate (SUC) was $10 \mathrm{mM}$, cytochrome c $40 \mu \mathrm{M}$, digitonin (DIG) $5 \mathrm{mg} / \mathrm{mg}$ protein, idebenone (IDB) $20 \mu \mathrm{M}$ and KCN $2 \mathrm{mM}$.

transfers electrons between NADH and flavoproteindependent dehydrogenases and Complex III (Lenaz and Genova 2009) and cyt $c$ that transfers electrons between Complex III and Complex IV (cytochrome $c$ oxidase) (Hüttemann et al. 2011). A lipophilic CoQ embedded in the membrane lipid bilayer can be a limiting factor for the respiratory chain function when its biogenesis is depressed by altered activity of enzymes participating on its synthesis. Several mitochondrial diseases due to the primary or secondary $\mathrm{CoQ}$ deficiency were described up to now (Quinzii and Hirano 2010, Rötig et al. 2007). A hydrophilic heme-protein cyt $c$ localized on the external surface of the inner membrane can be easily released by a disruption of the outer mitochondrial membrane albeit a very small portion $(11.2 \pm 2.1 \%)$ of cyt $c$ still persist bound on the inner mitochondrial membrane (Cortese et al. 1995). Recently, Benard et al. (2008) described three different mobile pools of both cyt $c$ and $\mathrm{CoQ}$ in rat liver and
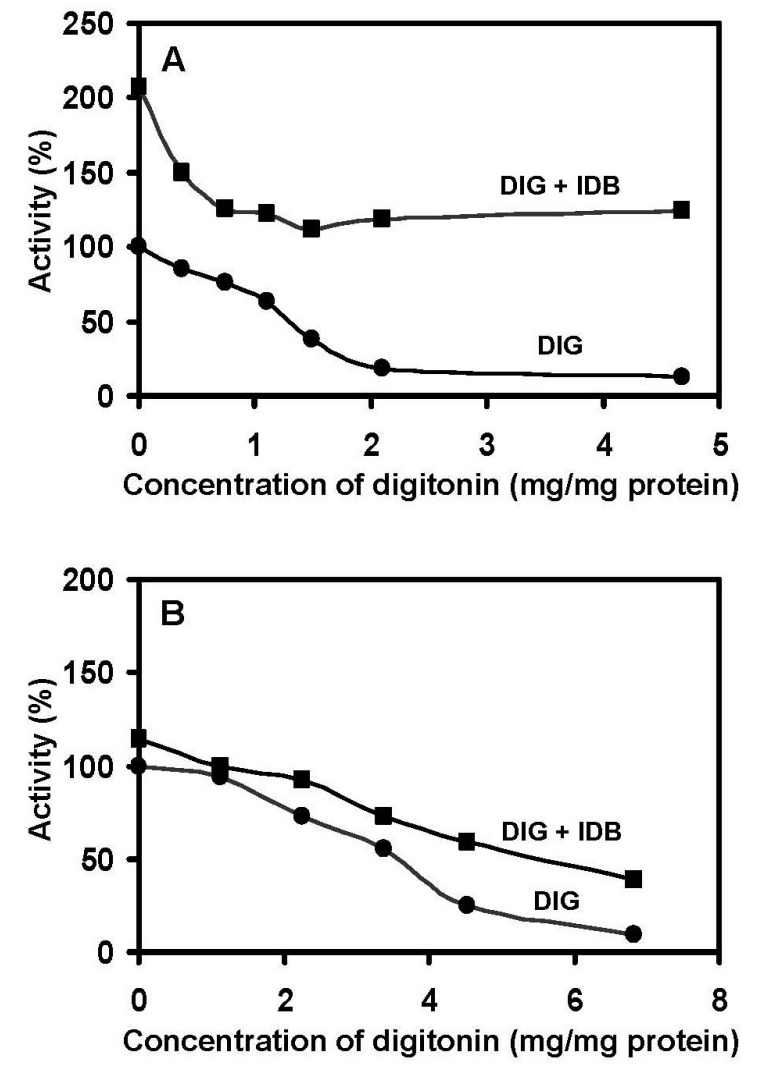

Fig. 4. (A) Digitonin inhibition (DIG) and idebenone release (DIG+IDB) of glycerol-3-phosphate cyt $c$ oxidoreductase, (B) Digitonin inhibition (DIG) and idebenone release (DIG+IDB) of succinate cyt $c$ oxidoreductase. In incubation medium glycerol3-phosphate or succinate was $25 \mathrm{mM}$, cytochrome c $20 \mu \mathrm{M}$, idebenone $20 \mu \mathrm{M}$ and $\mathrm{KCN} 2 \mathrm{mM}$.

muscle mitochondria what have implications for understanding the function of oxidative phosphorylation, cell physiology and pathology of mitochondrial diseases.

We tried to find experimental model conditions under which CoQ and cyt $c$ deficiency can be repaired and the electron flux restored. We used a disintegration of the mitochondrial membrane by a mild non-ionic detergent digitonin because under these conditions both CoQ and cyt $c$ are not able to maintain connection between particular complexes and participate in electron transfer to Complex IV. Several studies describe that an application of CoQ or its less hydrophobic derivative IDB has beneficial effects in mitochondrial diseases (Geromel et al. 2002, Kerr 2010).

Our data showed that exogenous IDB together with cyt $c$ can restore the electron transport between two flavoprotein-dependent enzymes and Complex IV, when the integrity of the respiratory chain was damaged by a detergent action and the oxidase activity strongly depressed. Obtained results also support the idea that the mechanism of the electron transport between two 
flavoprotein-dependent enzymes (GPDH and SDH) is not identical. Glycerol-3-phosphate-dependent electron transport is more sensitive to detergent damage than succinate-dependent one. The difference could be due to the presence of Q-binding protein on succinate dehydrogenase complex that was not identified on GPDH. In addition, different localization of SDH and GPDH on the inner mitochondrial membrane could play a role.

\section{Conflict of Interest}

There is no conflict of interest.

\section{References}

ACÍN-PÉREZ R, FERNÁNDEZ-SILVA P, PELEATO ML, PÉREZ-MARTOS A, ENRIQUEZ JA: Respiratory active mitochondrial supercomplexes. Mol Cell 32: 529-539, 2008.

BENARD G, FAUSTIN B, GALINIER A, ROCHER C, BELLANCE N, SMOLKOVA K, CASTEILLA L, ROSSIGNOL R, LETELLIER T: Functional dynamic compartmentalization of respiratory chain intermediate substrates: Implications for the control of energy production and mitochondrial diseases. Int J Biochem Cell Biol 40: 1543-1554, 2008.

CORTESE JD, VOGLINO AL, HACKENBROCK CR: Persistence of cytochrome c binding to membranes at physiological mitochondrial intermembrane space ionic strength. Biochim Biophys Acta 1228: 216-228, 1995.

COTTINGHAM IR, RAGAN CI: The reconstitution of L-3-glycerophosphate-cytochrome $c$ oxidoreductase from L-3glycerophosphate dehydrogenase, ubiquinone-10 and ubiquinol-cytochrome $c$ oxidoreductase. Biochem J 192: 19-31, 1980.

Di PROSPERO NA, SUMNER CJ, PENZAK SR, RAVINA B, FISCHBECK KH, TAYLOR JP: Safety, tolerability, and pharmacokinetics of high-dose idebenone in patients with Friedreich ataxia. Arch Neurol 64: 803-808, 2007.

EUBEL H, HEINEMEYER J, SUNDERHAUS S, BRAUN HP: Respiratory chain supercomplexes in plant mitochondria. Cell Physiol Biochem 42: 937-942, 2004.

GEELEN MJH: The use of digitonin-permeabilized mammalian cells for measuring enzyme activities in the course of studies on lipid metabolism. Anal Biochem 347: 1-9, 2005.

GEROMEL V, DARIN N, CHRÉTIEN D, BÉNIT P, DELONLAY P, RÖTIG A, MUNNICH A, RUSTIN P: Coenzyme $\mathrm{Q}_{10}$ and idebenone in the therapy of respiratory chain diseases: rationale and comparative benefits. Mol Genet Metab 77: 21-30, 2002.

HAGINOYA K, MIYABAYASHI S, KIKUCHI M, KOJIMA A, YAMAMOTO K, OMURA K, UEMATSU M, HINO-FUKOYO N, TANAKA S, TSUCHIYA S: Efficacy of idebenone for respiratory failure in a patient with Leigh syndrome: a long-term follow-up study. J Neurol Sci 278: 112-114, 2009.

HÜTTEMANN M, PECINA P, RAIBOLT M, SANDERSON TS, KAZAN VE, SAMAVATI L, DOAN JW, LEE I: The multiple function of cytochrome $\mathrm{c}$ and their regulation in life and death decision of the mammalian cell: From respiration to apoptosis. Mitochondrion 11: 369-381, 2011.

JOHNSON D, LARDY H: Isolation of liver or kidney mitochondria. Methods Enzymol 10: 94-96, 1967.

KERR DS: Treatment of mitochondrial electron transport chain disorders: A review of clinical trials over the past decade. Mol Genet Metab 99: 246-255, 2010.

LEE YP, LARDY H: Influence of thyroid hormones on L- $\alpha$-glycerophosphate dehydrogenase and other dehydrogenases in various organs of the rat. J Biol Chem 240: 1427-1436, 1965.

LEE YP, TAKEMORI AE, LARDY H: Enhanced oxidation of $\alpha$-glycerophosphate by mitochondria of thyroid-fed rats. J Biol Chem 234: 3051-3054, 1959. 
LENAZ G, GENOVA ML: Mobility and function of Coenzyme Q (ubiquinone) in the mitochondrial respiratory chain. Biochim Biophys Acta 1787: 563-573, 2009.

LENAZ G, GENOVA ML: Structure and organization of mitochondrial respiratory chain: a new understanding of an old subject. Antioxid Redox Sign 12: 961-1008, 2010.

LENAZ G, BARACCA A, BARBERO G, BERGAMINI C, DALMONTE ME, Del SOLE M, FACCIOLI M, FALASCA A, FATO R, GENOVA ML, SGARBI G, SOLAINI G: Mitochondrial respiratory chain supercomplex I-III in physiology and pathology. Biochim Biophys Acta 1797: 633-640, 2010.

LOWRY OH, ROSEBROUGH JN, FARR AL, RANDALL RJ: Protein measurement with the Folin-phenol reagent. J Biol Chem 193: 265-275, 1951.

LYNCH DR, PERLMAN SL, MEIER T: A phase 3, double-blind, placebo-controlled trial of idebenone in Friedreich ataxia. Arch Neurol 67: 941-947, 2010.

MASHIMA Y, KIGASAWA K, WAKAKURA M, OGUCHI Y: Do idebenone and vitamin therapy shorten the time to achieve visual recovery in Leber hereditary optic neuropathy? J Neuroophthalmol 20: 166-170, 2000.

QUINZII CM, HIRANO M: Coenzyme Q and mitochondrial disease. Dev Disabil Res Rev 16: 183-188, 2010.

RAUCHOVÁ H, BATTINO M, FATO R, LENAZ G, DRAHOTA Z: Coenzyme Q-pool function in glycerol-3phosphate oxidation in hamster brown adipose tissue mitochondria. J Bioenerg Biomembr 24: 235-241, 1992.

RAUCHOVÁ H, DRAHOTA Z, RAUCH P, FATO R, LENAZ G: Coenzyme Q releases the inhibitory effect of free fatty acids on mitochondrial glycerophosphate dehydrogenase. Acta Bioch Pol 50: 405-413, 2003.

RAUCHOVÁ H, ZACHAŘOVÁ G, SOUKUP T: Influence of chronically altered thyroid status on the activity of liver mitochondrial glycerol-3-phosphate dehydrogenase in female inbred Lewis rats. Horm Metab Res 36: 286-290, 2004.

RAUCHOVÁ H, VRBACKÝ M, BERGAMINI C, FATO R, LENAZ G, HOUŠTĚK J, DRAHOTA Z: Inhibition of glycerophosphate-dependent $\mathrm{H}_{2} \mathrm{O}_{2}$ generation in brown fat mitochondria by idebenone. Biochem Biophys Res Commun 339: 362-366, 2006.

RAUCHOVÁ H, DRAHOTA Z, BERGAMINI C, FATO R, LENAZ G: Modification of respiratory-chain enzyme activities in brown adipose tissue mitochondria by idebenone (hydroxydecyl-ubiquinone). $J$ Bioenerg Biomembr 40: 85-93, 2008.

RAUCHOVÁ H, MRÁČEK T, NOVÁK P, VOKURKOVÁ M, SOUKUP T: Glycerol-3-phosphate dehydrogenase expression and oxygen consumption in liver mitochondria of female and male rats with chronic alteration of thyroid status. Horm Metab Res 43: 43-47, 2011 a.

RAUCHOVÁ H, VOKURKOVÁ M, DRAHOTA Z: Idebenone restored mitochondrial glycerol-3-phosphate and succinate oxidoreductase activity inhibited by digitonin. FEBS J 278 (Suppl 1): 143, 2011 b.

RÖTIG A, MOLLET J, RIO M, MUNNICH A: Infantile and pediatric quinone deficiency diseases. Mitochondrion 78: S112-S121, 2007.

SCHÄGGER H, PFEIFFER K: Supercomplexes in the respiratory chains of yeast and mammalian mitochondria. EMBO J 19: 1777-1783, 2000.

SUGIYAMA Y, FUJITA T: Stimulation of the respiratory and phosphorylating activities in rat brain mitochondria by idebenone (CV-2619), a new agent improving cerebral metabolism. FEBS Lett 184: 48-51, 1985.

VONCK J, SCHÄFER E: Supramolecular organization of protein complexes in the mitochondrial inner membrane. Biochim Biophys Acta 1793: 117-124, 2009.

YU CA, NAGAOKA S, YU L, KING TE: Evidence for the existence of a ubiquinone protein and its radical in the cytochromes b and c1 region in the mitochondrial electron transport chain. Biochem Biophys Res Commun 82: 1070-1078, 1978.

YU CA, YU L: Specific interaction between protein and ubiquinone in succinate-ubiquinone reductase. J Biol Chem 257: 6127-6131, 1982.

ZS-NAGY I: Chemistry, toxicology, pharmacology and pharmacokinetics of idebenone: a review. Arch Gerontol Geriatr 11: 177-186, 1990. 